\title{
Natural-born scientists
}

Although Warp Drive has been pushing the commercial envelope of natural-products discovery, academic scientists have largely been the ones pushing the biology. Researchers at universities around the world have moved beyond simply hunting for new organisms and their compounds and have instead melded discovery with recombinant DNA technologies to sometimes produce unseen compounds, or even manufacture compounds that neither natural organisms nor chemists could have made on their own.

"Some of the dreams to make new molecules with altered properties have been realized," says William Gerwick, a marine natural-products scientist at the University of California-San Diego (UCSD).

For example, Sean Brady, a chemical biologist at Rockefeller University in New York, sifted through all the bacterial genes found in a clump of dirt he'd collected in Arizona and found one gene cluster of unknown function that looked particularly enticing on the basis of its predicted molecular structure. Brady and his team transferred this enigmatic gene cluster into an industrial strain of Streptomyces and, reporting last year, showed that it actually coded for a powerful antibiotic that was effective against the methicillin-resistant Staphylococcus aureus superbug (J. Am. Chem. Soc. 134, 19552-19555, 2012).

Findings like these demonstrate how novel drugs are often hiding in plain sight, notes Brady. "We literally don't know what bug it came from," he says.

Other scientists have turned discovery into engineering. Brad Moore, a UCSD biochemist who works with Gerwick, studies a group of bacteria called Salinispora that lives in deep-sea sediment and produces a cancer agent now in phase 1 trials for multiple myeloma and other kinds of tumors. By modifying the gene clusters responsible for this compound, Moore has added a fluorine atom to the molecule's composition, a tweak that may allow the human body to better metabolize the resulting drug (J. Nat. Prod. 73, 378-382, 2010).

"We now have a system where we can actually engineer a natural compound into a designer molecule," Moore says. -DG

form the backbone of many antibiotics and other natural products, they could engineer Escherichia coli to produce nearly a hundred different 'unnatural' natural compounds-a hugely promising feat for the world of natural products (Nat. Biotech. 23, 1171-1176, 2005). “These were angels on the head of a pin in terms of amount," says David Newman, chief of the natural products branch at the US National Cancer Institute in Fredrick, Maryland. "But they showed it could be done."

The achievement, however, did not save Khosla's startup, a Haywood, California-based firm called Kosan Biosciences. Kosan's naturally derived

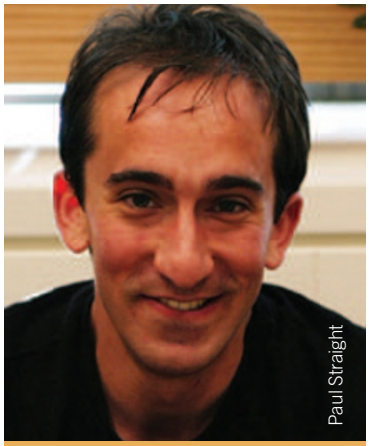

"Genome mining is just beginning to be anything other than science fiction. Michael Fischbach anticancer medicine advanced to phase 3 testing for the treatment of multiple myeloma. But Bristol-Myers Squibb, the New York-based pharma giant that bought the company in 2008, abandoned development of the drug, as it proved difficult to manufacture and was soon to lose patent protection. Now, most of the company's other technology has been shelved, too.

The story behind Biotica Technology of Cambridge, UK, which also used genomics to produce novel natural products, runs in the same vein. With none of its compounds clinically tested, the company exhausted all of its funds and was placed into administration earlier this year. (It was purchased by Sweden's NeuroVive for an undisclosed sum last month.)

Despite the failures of predecessors, Borisy and Verdine are so confident about bringing back the heyday of natural products that they trademarked and printed it on their business cards: "The reemergence of natural products in the era of genomics." Others seem to be jumping on the natural-products genomics bandwagon, too. Last month, for instance, the US National Institutes of Health announced close to $\$ 7$ million in new funding to support three projects under the banner title "Genomes to Natural Products." And, with less-directed government support, many academic groups are forging ahead with research programs in this emergent field, as well (see 'Natural-born scientists').

Yet, before other large pharmaceuticals join Sanofi in investing in natural products genomics, Warp Drive will have to show success in producing the molecules it's seeking-and, if it fails, companies will have to reassess the value of genomics in drug discovery.

Back at Warp Drive headquarters, Borisy puts on his coat to leave the scene of construction. But before he does, he stands behind a sweeping new orange reception desk intentionally designed to resemble furniture from the 1960s Star Trek television series that popularized the faster-than-light propulsion system behind the company's name. "Beam me up, Scotty," he says, laughing, and leaves the building.

Daniel Grushkin is a freelance writer in Brooklyn, New York. 